\title{
Hasil Luaran Operasi Pulltrough pada Hirsprung dengan Skoring Klotz di RSUD Arifin Achmad Pekanbaru (2010-2016)
}

\section{The Outcome of Pulltrough Surgery on Hirsprung Disease with Klotz Scoring at Arifin Achmad Hospital Pekanbaru (2010-2016)}

\author{
Tubagus Odih Rhomdani Wahid ${ }^{1 *}$ \\ ${ }^{1} \mathrm{KJF}$ Bedah Fakultas Kedokteran Universitas Riau
}

\begin{abstract}
ABSTRAK
Penyakit Hirschprung adalah suatu kelainan bawaan berupa aganglionosis usus, mulai dari sfingter ani internal ke arah proksimal dengan panjang yang bervariasi, bersifat kosmopolitan, dengan insiden berkisar 1 diantara 2000 sampai 12.000 kelahiran. Penelitian ini bertujuan untuk mengevaluasi hasil luaran operasi pulltrough pada Hirsprung dengan skor Klotz periode januari 2010-Desember 2016, meliputi hubungan status gizi dengan hasil luaran dan komplikasi yang timbul. Penelitian ini dilakukan dengan rancangan deskriptif analitik dengan pengumpulan data secara retrospektif terhadap penderita Hirschprung yang dikerjakan terapi definitif dengan metode operasi pulltrough, data diambil dari rekam medis dan kuisioner di RS Arifin Achmad periode Januari 2010- Desember 2016. Dua puluh sembilan pasien terdapat 16 (55,2 \%) pasien laki - laki dan $13(44,8 \%)$ pasien perempuan. Terdapat $21(72,4 \%)$ dengan gizi baik dan $8(27,6 \%)$ dengan gizi kurang. Komplikasi yang terbanyak ditemukan adalah enterokolitis $5(17,2 \%)$ diikuti dengan stenosis rectum $1(3,4 \%)$. Terdapat hubungan bermakna komplikasi pasca operasi pulltrough dengan evaluasi skoring Klotz dan tidak terdapat hubungan bermakna antara status gizi dengan evaluasi skoring Klotz.
\end{abstract}

Kata kunci: hirsprung, komplikasi, skoring Klotz

\begin{abstract}
Hirschprung's disease is a congenital abnormality of intestinal aganglionosis, starting from internal sphincter to proximal with varying length, cosmopolitan disease, with incidence ranging 1 in 2000 to 12,000 births. The aim of this study is to evaluate the outcome of pulltrough surgery on Hirsprung with Klotz scoring period January 2010 to December 2016, icluding the relationship of nutritional status with outcome and complication. This study was conducted with descriptive analytic design with retrospective data collection on Hirschprung patients who performed definitive therapy using pulltrough method. Data retrieved from medical record and questionnaire at Arifin Achmad Hospital. Twenty-nine patients there were 16 (55. 2\%) male patients and 13 (44.8\%) female patients. There were 21 (72.4\%) with good nutrition and 8 (27.6\%) with less nutrition. The frequently complication was enterocolitis 5 (17.2\%) followed by rectum stenosis 1 (3.4\%). There was a significant correlation between posttest pulltrough complications with Klotz scoring evaluation and no significant association between nutritional status and Klotz scoring evaluation.
\end{abstract}

Keywords: complication, hirsprung, Klotz scoring

*Korespondensi: Tubagus Odih Rhomdani Wahid, email: tubaguswahid@gmail.com

Artikel info: Online published first 25 April 2018 Received 1 Februari 2018; Accepted 6 Maret 2018.

DOI: https://doi.org/10.26891/jkm.v1i2.2018.93-98

Copyright @ 2018 Tubagus Odih Rhomdani Wahid. This is an open access article distributed under the terms of the Creative Commons Attribution-NonCommercial 4.0 International License (http://creativecommons.org/licenses/by-nc/4.0/), which permits unrestricted noncommercial use, distribution, and reproduction in any medium, provided the original author and source are properly cited. 
Penyakit Hirschprung adalah suatu kelainan bawaan berupa aganglionosis usus, mulai dari sfingter ani internal ke arah proksimal dengan panjang yang bervariasi. Disebut juga megacolon congenital, merupakan kelainan tersering yang dijumpai sebagai penyebab obstruksi usus pada neonatus. Pada penyakit ini tidak dijumpai pleksus myenterikus sehingga bagian usus tersebut tidak dapat mengembang. Setelah penemuan kelainan histologi ini barulah muncul teknik operasi yang rasional dari penyakit ini ${ }^{1,2}$

Manifestasi klinisnya adalah gangguan pasase usus fungsional. Penyakit ini bersifat kosmopolitan, dalam kepustakaan disebutkan bahwa insiden penyakit ini berkisar 1 diantara 2000 sampai 12.000 kelahiran, dengan insiden tersering 1 di antara 5000 kelahiran. Data tentang penyakit Hirschprung di Indonesia belum ada. Angka insidensi 1 diantara 5000 kelahiran maka dengan penduduk 220 juta dan tingkat kelahiran 35 per mil, diperkirakan akan lahir 1400 bayi setiap tahun dengan penyakit Hirschprung di Indonesia. Di Amerika frekuensi 1 dari 5000 kelahiran ${ }^{2,3,4}$

Pengobatan definitif aganglionosis kolon adalah pembedahan dengan membuang semua bagian yang aganglionik, kemudian membawa usus (kolon) yang normal persarafannya (ganglionik) ke anus dengan memperhatikan kontinensi, hal ini penting karena ada komplikasi yang dapat timbul sehingga dapat menggangu kualitas hidup kondisi kontinensia ini dapat dievaluasi dengan skor Klotz. Beberapa prosedur operasi penyakit Hirschprung antara lain: Prosedur Swenson, Prosedur Duhamel, Prosedur Boley dan Prosedur Soave yang semuanya dikenal dengan istilah Pulltrough. ${ }^{3,4}$

Dengan memperhatihan hal hal tersebut perlu evaluasi bagaimana hasil luaran operasi pulltrough pada Hirsprung periode januari 2010-Desember 2016 di RSUD Arifin Achmad Pekanbaru Riau dan faktor apa saja yang berpengaruh terhadap hasil luaran tersebut. Penelitian ini bertujuan untuk mengevaluasi hasil luaran operasi pulltrough pada Hirsprung dengan skor Klotz periode januari 2010Desember 2016, meliputi hubungan status gizi dengan hasil luaran dan komplikasi yang timbul. Dengan didapatkannya hasil evaluasi tersebut diharapkan dapat dijadikan referensi khususnya bagi klinisi bedah anak dalam penanganan definitif hirsprung khususnya teknik operasi pulltrough sehingga dapat dijadikan salah satu penjelasan terutama prognosis pasca operasi.

\section{METODE}

Penelitian ini dilakukan dengan rancangan deskriptif analitik dengan pengumpulan data secara retrospektif terhadap penderita Hirschprung yang dikerjakan terapi definitif dengan metode operasi pulltrough periode bulan Januari 2010 sampai Desember 2016. Pemilihan subjek penelitian yakni semua pasien anak yang telah tegak terdiagnosis hirsprung, yang dirawat di bagian Bedah Anak RSUD Arifin Achmad periode Januari 2010 sampai Desember 2016 dan telah dioperasi dengan metode pulltrough. Data dikumpulkan dari rekam medik disertai dengan kesediaan orang tua mengikuti penelitian. Data penelitian dikumpulkan dan dicatat dalam formulir penelitian. Data deskriptif disajikan secara tesktular dan tabular serta dilakukan analisa data.

\section{HASIL DAN PEMBAHASAN}

Selama periode penelitian yaitu dari bulan januari 2010 sampai Desember 2016 di Bedah anak didapatkan 127 pasien Hischprung. Dari jumlah tersebut 88 pasien telah dilakukan operasi kolostomi dan operasi definitif, 2 pasien meninggal setelah dikerjakan operasi definitif, 15 pasien dilakukan kolostomi, 3 pasien meninggal setelah dilakukan operasi kolostomi, 5 meninggal sebelum dilakukan operasi sama sekali dan 11 pasien pulang paksa dan menolak tindakan.

Tabel 1. Karakteristik pasien Hirschprung yang menjalani kolostomi

\begin{tabular}{lcc}
\hline \multicolumn{1}{c}{ Variabel } & $\mathbf{n}$ & $\mathbf{\%}$ \\
\hline $\begin{array}{l}\text { Jenis Kelamin } \\
\text { Laki-laki }\end{array}$ & 16 & 55,2 \\
Perempuan & 13 & 44,8 \\
Umur & & \\
$\quad$ < 1 bulan & 11 & 37,9 \\
1-6 bulan & 8 & 27,6 \\
6 bulan -1 tahun & 1 & 3,4 \\
$\quad>1$ tahun & 9 & 31,0 \\
Berat lahir & & \\
< 2500 gram & 0 & 0 \\
$2500-2999$ gr & 14 & 48,8 \\
3000 - 3449 gr & 13 & 44,8 \\
3500 - 3999 gr & 1 & 3,4 \\
$\quad>4000$ gr & 1 & 3,4 \\
Status gizi & & \\
Baik & 21 & 72,4 \\
Kurang & 8 & 27,6 \\
\hline
\end{tabular}

Karakteristik pasien Hirschprung yang menjalani kolostomi menurut jenis kelamin dapat dilihat pada Tabel 1. Dari 88 pasien, 29 (32\%) dapat dilakukan evaluasi fungsi anorektal/kontinensia, sedangkan 59 (68\%) pasien tidak bisa dievaluasi karena 57 tidak 
bersedia dan tempat tinggal jauh, 1 pasien meninggal pasca operasi definitif dan 1 pasien tidak kontrol serta tak bisa dihubungi. Dari 29 Pasien tersebut terdapat $16(55,2 \%)$ pasien laki - laki dan $13(44,8 \%)$ pasien perempuan. Pada penelitian ini, dari 29 pasien yang diobservasi, 11 pasien berusia kurang dari 1 bulan, 8 pasien 1 sampai 6 bulan, 1 pasien 6 bulan sampai 1 tahun dan 9 pasien diatas 1 tahun. Dua puluh sembilan pasien tidak didapatkan pasien yang mempunyai berat lahir kurang dari 2500 gram, semuanya memiliki berat lahir di atas 2500 gram. Jadi dari 29 pasien $100 \%$ berat badannya di atas 2500 gram. Status Gizi, dari 29 pasien, terdapat $21(72,4 \%)$ dengan gizi baik dan $8(27,6 \%)$ dengan gizi kurang.

Riwayat pengeluaran mekoneum diperoleh 3 kasus $(10,3 \%)$ yang evakuasi mekoneum pertamanya terjadi dalam 24 jam setelah lahir, selebihnya $(89,7 \%)$ evakuasi mekoneum terjadi setelah 24 jam.

Tabel 2. Distribusi gambaran radiologis lokasi daerah

\begin{tabular}{lcc}
\multicolumn{1}{c}{ transisi } & $\mathbf{n}$ & $\%$ \\
\hline Lokasi & 3 & 11,2 \\
\hline Rektum & 18 & 62,2 \\
Rektosigmoid & 7 & 23,2 \\
Sigmoid & 1 & 3,4 \\
Kolon descendens-Ascendens & 29 & 100 \\
\hline Jumlah & & \\
\hline
\end{tabular}

Berdasarkan pemeriksaan radiologis didapatkan lokasi daerah transisi terbanyak adalah pada rektosigmoid yaitu 18 (62,2\%) kasus.

Evaluasi pasien pasca operasi dapat dilihat pada Tabel 3. Pada penelitian ini didapatkan 16 (55,1\%) pasien frekuensi defekasinya normal yaitu 1 sampai dengan 2 kali sehari, 4 (13,7\%) defekasi 2 hari sekali, $7(24,2 \%)$ frekuensi defekasi 3-5 kali sehari, 1 pasien 3 hari sekali, 1 pasien 4 hari sekali, dan tidak ada pasien yang defekasi 5 hari sekali. Kondisi kembung,menunjukan bahwa $69 \%$ pasien tidak lagi mengeluh kembung. Sejumlah 8 (27,6 \%) kadangkadang masih kembung serta 1 (3,4 \%) pasien masih mengeluh kembung. Konsistensi feses, lebih dari separuh pasien memiliki konsistensi feses normal pascaoperasi, sedangkan 34\% dengan konsistensi lembek. Hanya $14 \%$ pasien yang konsistensi fesesnya encer setelah menjalani pembedahan. Perasaan ingin buang air besar, sebanyak $22(75,8 \%)$ pasien dapat merasakan apabila ingin buang air besar, terdapat $7(24,2 \%)$ pasien yang tidak bisa merasakan bila ingin buang air besar Soiling (keciprit) bersama flatus terdapat pada 9 (31,0\%) pasien, 18 (62,2\%) pasien tidak terdapat soiling, dan $2(6,8 \%)$ pasien terjadi soiling yang terus-menerus. Kemampuan menahan feses yang keluar, Terdapat 19 (64,6\%) pasien yang bisa menahan buang air besar lebih dari 1 menit, 7 (24,2\%) pasien bisa menahan kurang dari 1 menit dan terdapat $3(11,2 \%)$ pasien yang tidak bisa menahan buang air besar.

Tabel 3. Evaluasi pasien pasca operasi

\begin{tabular}{lcc}
\hline \multicolumn{1}{c}{ Klinis } & $\mathbf{n}$ & \% \\
\hline Defekasi & 16 & 55,1 \\
1-2 kali sehari & 4 & 13,7 \\
2 hari sekali & 7 & 24,2 \\
3-5 kali sehari & 1 & 3,4 \\
3 hari sekali & 1 & 3,4 \\
4 hari sekali & 0 & 0 \\
5 hari sekali & & \\
Kembung & 20 & 69,0 \\
Tidak pernah & 8 & 27,6 \\
Kadang-kadang & 1 & 3,4 \\
Terus menerus & & \\
Konsistensi feses & 15 & 51,7 \\
Normal & 10 & 34 \\
Lembek & 4 & 14,3 \\
Encer & 0 & 0 \\
Keras & & \\
Defekasi & 22 & 75,8 \\
Terasa & 7 & 24,2 \\
Tidak terasa & & \\
Soiling & 18 & 62,2 \\
Tidak pernah & 9 & 31,0 \\
Bersama flatus & 2 & 6,8 \\
Terus menerus & & \\
Menahan feses & 19 & 64,6 \\
Lebih dari 1 menit & 7 & 24,2 \\
Kurang dari 1 menit & 3 & 11,2 \\
Tidak bisa menahan & 3 & \\
\hline
\end{tabular}

Evaluasi 29 pasien pasca operasi dengan skoring Klotz disajikan pada Tabel 4. Penelitian ini menunjukkan skoring Klotz adalah: sangat baik 14 pasien $(48,3 \%)$, baik 4 pasien $(13,8 \%)$, cukup 9 pasien $(31,0 \%)$ dan nilai skoring Klotz kurang terdapat pada 2 pasien $(6,9 \%)$.

Tabel 4. Distribusi subyek menurut hasil Skoring Klotz

\begin{tabular}{lcc}
\hline \multicolumn{1}{c}{ Hasil Skoring klotz } & $\mathbf{n}$ & $\%$ \\
\hline Sangat baik & 14 & 48,3 \\
Baik & 9 & 13,8 \\
Cukup & 9 & 31,0 \\
Kurang & 2 & 6,9 \\
\hline
\end{tabular}

Tabel 5 memperlihatkan distribusi frekuensi umur definitif, rentang waktu operasi, lama rawat inap dan komplikasi. Operasi definitif $58.8 \%$ usia lebih dari 12 bulan, lebih kepada pertimbangan toleransi trauma pasca operasi. Sebagian besar rentangan waktu kapan dikolostomi sampai definitif adalah lebih dari 6 bulan (65\%). Lebih dari tiga perempat pasien dirawat inap kurang dari 10 hari (75,9\%). Dari 6 kasus yang menderita komplikasi, 5 kasus menderita enterocolitis dan 1 kasus stenosis rektum. 
Tabel 5. Distribusi frekuensi umur definitif, rentang waktu operasi, lama rawat inap dan komplikasi

\begin{tabular}{lcc}
\hline Variabel & $\mathbf{n}$ & $\%$ \\
\hline Umur definitif & & \\
$<=12$ bulan & 12 & 41,4 \\
> 12 bulan & 17 & 58,6 \\
Rentang waktu & & \\
$<=6$ bulan & 10 & 34,5 \\
$>\quad 6$ bulan & 19 & 65,5 \\
Lama rawat inap & & \\
$<=10$ hari & 22 & 75,9 \\
$>\quad 10$ hari & 7 & 24,1 \\
Komplikasi & & \\
Ya & 6 & 21 \\
Tidak & 23 & 79 \\
\hline
\end{tabular}

Tabel 6. Hubungan antara skoring Klotz dengan jenis kelamin, status gizi, dan komplikasi

\begin{tabular}{lccccc}
\hline \multicolumn{1}{c}{ Variabel } & \multicolumn{2}{c}{ Baik } & \multicolumn{2}{c}{ Kurang } & P \\
& n & $\%$ & n & $\%$ & \\
\hline Jenis kelamin & & & & & \\
Laki-laki & 9 & 50 & 7 & 63,6 & 0,702 \\
$\begin{array}{l}\text { Perempuan } \\
\text { Status gizi }\end{array}$ & 9 & 50 & 4 & 36,6 & \\
Baik & 14 & 77,8 & 7 & 63,6 & 0,433 \\
Kurang & 4 & 22,2 & 4 & 22,2 & \\
Komplikasi & & & & & \\
Ya & 1 & 5,6 & 5 & 45,5 & 0,018 \\
Tidak & 17 & 94,4 & 6 & 54,5 & \\
\hline
\end{tabular}

Pada tabel 6 hanya didapatkan hubungan yang bermakna antara komplikasi dengan skoring Klotz $(p=0,018)$, sedangkan jenis kelamin dan status gizi tidak didapatkan hubungan yang bermakna.

Jenis Kelamin, dari 29 pasien, terdiri dari 16 laki-laki dan 13 perempuan atau dengan rasio 1,23: 1 . Menurut penelitian Edward, dalam studinya melaporkan bahwa perbadingan laki-laki dan perempuan 4,5: $1^{5}$. Penelyian lainnya laki-laki 83,5 \%dan wanita $16,5 \%{ }^{6,7}$, sedangkan Foster mendapatkan hasil $76 \%$ laki-laki dan $23 \%$ perempuan $^{8}$, lainnya angka perbandingan laki-laki dan perempuan 2,97: $: 1^{2}$. Dari semua penelitian tersebut menunjukkan bahwa jumlah penderita Hischprung pada laki-laki lebih besar dari pada perempuan.

Kolostomi pada Hischprung dikerjakan awal setelah diagnosis ditegakkan. Kolostomi dibuat dengan tujuan untuk sarana dekompresi dan diversi. Sebagai sarana dekompresi untuk menghilangkan gejala distensi karena penimbunan gas dan feses. Pada penelitian ini, dari 29 pasien yang diobservasi, 11 pasien dikerjakan kurang dari 1 bulan, 8 pasien 1 sampai 6 bulan, 1 pasien 6 bulan sampai 1 tahun dan 9 pasien diatas 1 tahun. Dua puluh sembilan pasien tidak didapatkan pasien yang mempunyai berat lahir kurang dari 2500 gram, semuanya memiliki berat lahir di atas 2500 gram. Jadi dari 29 pasien $100 \%$ berat badannya di atas 2500 gram. Hasil ini sesuai dengan yang dilaporkan oleh Kartono yang menemukan bahwa pasien dengan berat baadan lahir >= 2500 gram 86,1 \%, sedangkan Swenson mendapatkan $82 \%$ dari 364 pasien. ${ }^{1,2}$

Riwayat pengeluaran mekoneum diperoleh 3 kasus $(10,3 \%)$ yang evakuasi mekoneum pertamanya terjadi dalam 24 jam setelah lahir, selebihnya $(89,7 \%)$ evakuasi mekoneum terjadi setelah 24 jam. Penelitian yang dilaporkan Swenson menemukan 6 $\%$, yang evakuasi mekoneum pertamanya dalam 24 jam. Pada bayi normal cukup bulan, evakuasi mekoneum terjadi dalam waktu 24 jam. Pada penyakit Hirschprung selain terdapat keterlambatan, seringkali memerlukan bantuan dengan colok dubur atau pemasangan pipa rektal. Penelitian Kartono mendapatkan $6,5 \%$ pasien yang mekoneumnya keluar sebelum 24 jam. Dengan demikian keterlambatan evakuasi mekoneum merupakan salah satu anamnesis yang tidak boleh dilupakan apabila menjumpai pasien dengan kecurigaan penyakit Hirschprung. ${ }^{1,2}$

Pemeriksaan Radiologi sangat membantu dalam penegakan diagnosis penyakit Hirschprung. Pemeriksaan foto polos abdomen didapatkan gambaran obstruksi letak rendah. Pada pemeriksaan barium enema terdapat gambaran klasik yaitu penyempitan, daerah transisi dengan dilatasi kolon di sebelah proksimalnya, disertai atau tanpa disertai tanda-tanda enterokolitis. Gambaran Radiologi zona transisi. Pada penelitian ini didapatkan lokasi daerah transisi rektosigmoid pada 18 (62,2 \%) kasus, jadi hampir sama dengan penelitian Kartono yang menemukan transisi rektosigmoid terdapat pada $57,9 \%$ pasien. Prosentase yang lebih besar dilaporkan oleh Sanjay yang menemukan transisi rektosigmoid terdapat $74-81 \%{ }^{2,9}$ Status Gizi, dari 29 pasien,terdapat $21(72,4 \%)$ dengan gizi baik dan 8 $(27,6 \%)$ dengan gizi kurang. Penilaian status gizi dapat dilakukan secara klinis, antropometri, biokimiawi dan biofisik ${ }^{10}$. Pada penelitian ini kami menggunakan penilaian antropometri dengan mengetahui berat badan pasien sebelum dilakukan operasi definitif dikonfirmasikan dengan umur dari pasien.

Evaluasi dari fungsi anorektal diamati 6 bulan pasca operasi. Pada penelitian ini didapatkan 16 (55,1\%) pasien frekuensi defekasinya normal yaitu 1 sampai dengan 2 kali sehari, 4 (13,7\%) defekasi 2 hari sekali, 7 (24,2\%) frekuensi defekasi 3-5 kali sehari, 1 pasien 3 hari sekali, 1 pasien 4 hari sekali, dan tidak ada pasien yang defekasi 5 hari sekali. 
Kebiasaan defekasi, menggambarkan adanya konstipasi yang berulang, dimana penderita tetap tidak dapat defekasi spontan sehingga harus tetap dibantu dengan pemberian laksansia atau dirangsang secara mekanis. Menurut Soave komplikasi tersering setelah operasi pullthrough adalah kembalinya konstipasi. Hal ini kemungkinan bagian yang aganglionosis pada bagian proksimal tidak seluruhnya terbuang atau pada saat melakukan pullthrough sfingter ani eksternus belum dilemaskan dengan baik ${ }^{2,11 .}$

Kembung menunjukan bahwa $69 \%$ pasien tidak lagi mengeluh kembung. Sejumlah 8 (27,6 \%) kadangkadang masih kembung serta $1(3,4 \%)$ pasien masih mengeluh kembung. Penelitian sebelumnya menyebutkan pasien yang masih terdapat keluhan kembung paska operasi sebesar 5,71\%, lainnya menyebutkan angka $21 \% .^{12}$ Konsistensi feses, lebih dari separuh pasien memiliki konsistensi feses normal pascaoperasi, sedangkan $34 \%$ dengan konsistensi lembek. Hanya $14 \%$ pasien yang konsistensi fesesnya encer setelah menjalani pembedahan. Kertiyasa menyatakan $47 \%$ untuk feses lembek, kemungkinan untuk anamnesis feses lembek sulit dipahami oleh orang tua penderita. Faktor lain yng menyebabkan feses lembek adalah jenis makanan yang dikonsumsi dan adanya infeksi intestinal. Terjadinya feses lembek pada pasien paska operasi pullthrough adalah rektum yang baru belum dapat sepenuhnya menyesuaikan diri dalam penyerapan air. ${ }^{13}$

Perasaan ingin buang air besar, sebanyak $22(75,8 \%)$ pasien dapat merasakan apabila ingin buang air besar, dan terdapat 7 (24,2\%) pasien yang tidak bisa merasakan bila ingin buang air besar. Soiling (keciprit) bersama flatus terdapat pada $9(31,0 \%)$ pasien, 18 (62,2\%) pasien tidak terdapat soiling, dan $2(6,8 \%)$ pasien terjadi soiling yang terus-menerus. Kertiyasa (1994) mengemukakan adanya soiling terjadi pada $47 \%$ pasien. Santos mengatakan soiling terjadi akibat sfingter internus yang telah dilemaskan tidak mampu melewatkan udara tanpa ikutnya feses encer. Soave) menyatakan bahwa soiling akibat dari cedera sfingter internus dan akan membaik dengan bertambahnya umur. Holsnider melaporkan soiling pada Boley prosedur adalah $1 \%{ }^{4,11,13}$

\section{DAFTAR PUSTAKA}

1. Swenson O, Sherman JO. Diagnosis of congenital megacolon : An analysis of 501 patients. J pediatric Surgery 1998. $8: 587-94$
Kemampuan menahan feses yang keluar, Terdapat $19(64,6 \%)$ pasien yang bisa menahan buang air besar lebih dari 1 menit, 7 (24,2\%) pasien bisa menahan kurang dari 1 menit dan terdapat 3 (11,2\%) pasien yang tidak bisa menahan buang air besar. Penelitian sebelumnya yang dilakukan Kertiyasa, terdapat $54 \%$ pasien yang tidak bisa menahan defekasi, secara teoritis reseptor sensoris di daerah rectum tidak terganggu. ${ }^{13}$

Evaluasi 29 pasien pasca operasi dengan skoring Klotz adalah: sangat baik 14 pasien (48,3\%), baik 4 pasien $(13,8 \%)$, cukup 9 pasien $(31,0 \%)$ dan nilai skoring Klotz kurang terdapat pada 2 pasien (6,9 \%). Karena jumlah sampelnya sedikit untuk uji statistik dibuat titik potong dijadikan dikotomi, sangat baik digabung dengan baik menjadi kriteria baik dan cukup digabung dengan kurang menjadi kriteria kurang.

Komplikasi, Pada penelitian ini komplikasi enterokolitis $17,2 \%$ dan menurut Holsnider enterokolitis sebesar $7 \%^{4}$, menurut Sanjay enterokolitis sebesar $13 \%{ }^{9}$, menurut. Murthi melaporkan enterokolitis 9\% dan stenosis $22 \% 15$ dan Tobari melaporkan enterokolitis 6,5\% dan stenosis $6,5 \% .{ }^{17}$ Didapatkan hubungan yang bermakna antara komplikasi dengan skoring Klotz $(p=0,018)$, yang lainya tidak didapatkan hubungan yang bermakna.

Satu pasien $(3,4 \%)$ terjadi komplikasi stenosis recti dan telah dilakukan koreksi dengan myektomi, dan 2 pasien $(6,8 \%)$ preoperasinya sudah ada enterokolitis. Menurut Kartono enterokolitis preoperasi akan mempengaruhi outcome dan dapat terjadi kembali setelah operasi. ${ }^{2}$

\section{SIMPULAN}

Terdapat hubungan bermakna komplikasi pasca operasi pulltrough dengan evaluasi skoring Klotz dan tidak terdapat hubungan bermakna antara status gizi dengan evaluasi skoring klotz.

\section{KONFLIK KEPENTINGAN}

Tidak ada

2. Kartono D. Penyakit hirschprung, perbandingan prosedur swenson dan duhamel modifikasi. (Disertasi). Universitas Indonesia. 1993. 
3. Yoshida CJr, Faintuch S, Lederman HM. Hirschprung disease imaging. (internet, update 5 November 2005) (cited 20 Desember 2017) available from: https://emedicine.medscape.com/article/409150overview

4. Holschider A, Ashcraft KW. Pediatric surgery. University of Missouri, Kansas City: 2000.

5. Edward T, Jefrry L. Hirrschprung disease : Associated abnormalities and demography. Harvard Medical School, Boston: 1990.

6. Lee Steven, MD,Hirschprung disease. University of California at Davis. 2003

7. Langer JC, Fitzgerald PG, Winthrop AL, Srinathan SK, Foglia RP, et al. One stage versus two stage soave pull through for hirschprung disease in the first year of life. J Pediatr Surg. 1996 Jan;31(1):33-6.

8. Diaz A, Edwards S, Neal WP, Elbirt P, Rappaport M, Kierstead R, Foster children with special needs: The Children's Aid Society experience. Mt Sinai J Med. 2004 May;71(3):166-9.

9. Naok S, Nitin G. Pediatric Surgery Diagnosis. Jay pee Brothers:New Delhi. 2000.

10. Paryanto, E.P, , Gizi dalam masa tumbuh kembang, Subbagian Gizi Anak RSUP Dr. sardjito, Yogyakarta. 1997.

11. Soave JW. The myenteric plexus in congenital megacolon. Procceding Staff meeting Mayo 13 : 123. 1988.

12. Wilcox DT, Kiely EM. Repeat pull thourgh for hirschprung. J Pediatr Surg. 1998 Oct;33(10):1507-9 .

13. Kertiyasa, Evaluasi hasil operasi endorectal pulltrhough Soave Modifikasi Soewarno di Laboratorium ilmu Bedah FK UGM Yogyakarta. Karya Ilmiah Paripurna. FK UGM, Yogyakarta. 1994

14. Santos MC, Giacomantonio JM, Lau HY. Primary swenson pull thourgh compared with multiple stage pull thourgh in neonate. J Pediatr Surg. 1999 Jul;34(7):1079-81.

15. Murthi GVS, Raine PAM. Preoperative enterocolitis is associated with poorer long-term bowel function after Soave-Boley endorectal pull-through for Hirschsprung's disease. Proceeding the 49th Annual Congress of the British Association of Paediatric Surgeons, Cambridge, England, July 23-26, 2002.

16. Tabari AK, Kebria MM. The Result of two stage surgical management of hirschprung disease in a 10 year period. Arch Irn Med 2001;4(2): 84-87. 